\title{
Characterization for enterotoxin production, virulence factors, and antibiotic susceptibility of Staphylococcus aureus isolates from various foods in Portugal
}

\author{
V. Pereira, C. Lopes, A. Castro, J. Silva, P. Gibbs, P. Teixeira* \\ Escola Superior de Biotecnologia - Universidade Católica Portuguesa, Rua Dr. António Bernardino de Almeida, 4200-072 Porto, Portugal
}

Keywords:

Staphylococcus aureus

Characterization

Enterotoxins

Virulence factors

Antibiotic susceptibilities

\begin{abstract}
A B S T R A C T
Staphylococcus aureus represents a public health challenge worldwide. The aim of this study was the characterization of different food isolates of $S$. aureus on the basis of their production of enterotoxins, hemolysins and resistance to antibiotics. A total of 148 coagulase-positive staphylococcal strains isolated from different food origins were identified to the species level. By multiplex PCR, $69 \%$ of the isolates were shown to be enterotoxigenic (SEs); the most common were sea seg, sea seg sei and seg sei. According to CLSI [CLSI, Clinical and Laboratory Standards Institute, 2007. Performance Standards for Antimicrobial Susceptibility Testing; Fifteenth Informational Supplement. CLSI document M100-S15. Clinical and Laboratory Standards Institute, Wayne, PA], 38\% of the isolates were resistant to oxacillin ( $\geq 6 \mu \mathrm{g} / \mathrm{mL}$; MRSA positives) but only $0.68 \%$ showed the presence of mecA gene. 70 and $73 \%$ of the $S$. aureus strains were resistant to $\beta$-lactams, ampicillin and penicillin, respectively. The virulence pattern was demonstrated to be origin and strain dependent. These findings emphasise the need to prevent the presence of S. aureus strains and SEs production in foods.
\end{abstract}

\section{Introduction}

Staphylococcus aureus is a common pathogen associated with serious community and hospital acquired diseases and has for long been considered as a major problem of Public Health (Pesavento et al., 2007). Some strains of this organism can cause foodpoisoning by production of enterotoxins (SEs) when growing in foods; SEs have been divided into different serological types initially SEA through SEE and later the existence of new types of SEs have also been reported (Monday and Bohach, 1999; Omoe et al., 2005; Chiang et al., 2006; Chiang et al., 2008).

Most of the nosocomial S. aureus infections are caused by methicillin-resistant $S$. aureus (MRSA) strains and have become a widely recognized cause of morbidity and mortality throughout the world (Ardic et al., 2006; Pesavento et al., 2007; Ho et al., 2008). In addition, MRSA strains resistant to quinolones or multiresistant to other antibiotics have been emerging, leaving a limited choice for their control (Mee-Marquet et al., 2004; Nejma et al., 2006; Pesavento et al., 2007).

Several virulence factors implicated in the pathogenesis of $S$. aureus strains, have been described in the literature (Kérouanton et al., 2007; Normanno et al., 2007; Vancraeynest et al., 2007) such as

\footnotetext{
* Corresponding author. Tel.: +351 22 5580095; fax: +351 225090351. E-mail address: pcteixeira@esb.ucp.pt (P. Teixeira).
}

thermonuclease, hyaluronidase, lipases and hemolysins (Sandel and McKillip, 2004; Kuroda et al., 2007), which are involved in tissue invasion of the host cells. Perhaps the most notable virulence factors associated with this microorganism are the heat-stable enterotoxins (SEs), that cause the sporadic food-poisoning syndrome or foodborne outbreaks, and the toxic shock syndrome toxin 1 (TSST-1), which diminishes the immune response of a colonized host (Tsen et al., 1998; Martin et al., 2003; Sandel and McKillip, 2004; Kérouanton et al., 2007; Vancraeynest et al., 2007). On the other hand, most of the severe $S$. aureus infections are due to the cumulative effects of several virulence determinants (Nejma et al., 2006).

The aim of the present study was the characterization of different S. aureus isolates collected from different food origins. This characterization was based on the ability of the isolates to produce and to express staphylococcal enterotoxins, on the antibiotic susceptibilities in order to determine the presence of MRSA strains, and on the presence of other virulence factors. Furthermore, the relationship between the different origins of the isolates and the ability of these isolates to produce virulence factors was also evaluated.

Materials and methods

Bacterial strains and media

From 2006 to 2008, different food products, mainly from the north of Portugal, were submitted to a routine microbiological lab 
(ESBUCP, Porto) for analyses of the presence of coagulase-positive staphylococci on Baird-Parker agar with rabbit plasma fibrinogen (BPA + RPF, bioMérieux, France). Two hundred and six colonies showing the typical appearance of coagulase-positive staphylococci were tested for Gram staining, catalase, coagulase and thermostable DNAse activity (Gündoğan et al., 2006). After this screening, 148 presumptive $S$. aureus isolates from raw meat $(n=15)$, traditional Portuguese fermented meat products $(n=65)$, cheeses ( $n=9$ ), bovine mastitis (from raw milk samples; $n=18$ ), raw cow's milk $(n=20)$ and other food products $(n=21)$ were stored in cryovials at $-80^{\circ} \mathrm{C}$ in Tryptone Soy Broth (TSB, Pronadisa, Spain) plus $30 \% \mathrm{v} / \mathrm{v}$ glycerol for further characterization. Working cultures were prepared by streaking directly from the cryovials onto Tryptone Soy Broth (TSB, Pronadisa) and incubating at $37^{\circ} \mathrm{C}$ for $24 \mathrm{~h}$.

\section{DNA isolation for PCR}

DNA template used for PCR analysis was isolated from the strains by the guanidine-isothiocyanate extraction method (Aires de Sousa et al., 1996).

\section{Identification by multiplex PCR}

The isolates were identified to the species level according to the multiplex PCR developed by Zhang et al. (2004). According to this PCR assay the presence of the target 16S rRNA (Staphylococcus genus specific), nuc (S. aureus species specific) and mecA (a determinant of methicillin resistance) was determined. S. aureus DSM 11729 was used as a positive control for gene mecA, Staphylococcus epidermidis DSM 20044 as a negative control for gene nuc and S. aureus ATCC 29213 as positive control for targeting 16S rRNA and nuc gene and negative for gene mecA.

\section{Detection of enterotoxin production}

$S$. aureus strains were studied for their ability to produce enterotoxins according to the VIDAS methodology and for the presence of the enterotoxin genes by multiplex PCR (Zhang et al., 2004).

\section{VIDAS methodology}

The enzyme-linked fluorescent assay (ELFA) using the automated VIDAS instrument was used for the specific detection of Staphylococcal enterotoxins (Staph enterotoxin II, SET 2, bioMérieux) according to the instructions of the manufacturer. In this test, complementary monoclonal and polyclonal antibodies directed to the 5 different staphylococcal enterotoxins SEA, SEB, SEC, SED and SEE are used for the capture and detection process without distinguishing individual toxins. One isolated colony of S. aureus was cultured in BHI broth for $24 \mathrm{~h}$ at $37^{\circ} \mathrm{C}$. The culture was centrifuged at $7000 \mathrm{~g}$ for $10 \mathrm{~min}$ at $4{ }^{\circ} \mathrm{C}$ and $500 \mu \mathrm{L}$ of the supernatant was then added to the initial VIDAS strip wells and further analysed by the automated method.

\section{Multiplex PCR}

The detection of staphylococcal enterotoxin genes in staphylococcal isolates was determined according to Løvseth et al. (2004) for the detection of enterotoxin genes A-E and G-J (Table 1). The amplification of the target 16S rRNA gene was included as the internal control. As positive controls, different strains of $S$. aureus kindly supplied by Prof. Løvseth (National Veterinary Institute, Norway) were used: R2102/00 for sec, seg, sei genes; R4571/00 for sec gene, FRI572 for seg, sei genes; 3169 for sec-bovine, sed, sej genes; FRI472 for sed, seg, sei, sej genes; R5371/00 for sea, seg, seh, sei genes; R963/00 for sed, seg, sei, sej genes; R5460/00 for seb, seg,
Table 1

Primers used in this study for detection of SE genes, and target 16S rRNA gene.

\begin{tabular}{|c|c|c|c|}
\hline Primer $^{\mathrm{a}}$ & Primer sequence $\left(5^{\prime}-3^{\prime}\right)$ & $\begin{array}{l}\text { Amplified product } \\
\text { size (bp) }\end{array}$ & $\begin{array}{l}\text { Multiplex PCR reaction } \\
\text { mixture no. }\end{array}$ \\
\hline $\begin{array}{l}\text { sea forw. } \\
\text { sea rev. }\end{array}$ & $\begin{array}{l}\text { GCA GGG AAC AGC TTT } \\
\text { AGG C } \\
\text { GTT CTG TAG AAG TAT } \\
\text { GAA ACA CG }\end{array}$ & 521 & 1 \\
\hline $\begin{array}{l}\text { seb-sec } \\
\text { forw. } \\
\text { seb-sec } \\
\text { rev. }\end{array}$ & $\begin{array}{l}\text { ACA TGT AAT TTT GAT ATT } \\
\text { CGC ACT G } \\
\text { TGC AGG CAT CAT ATC } \\
\text { ATA CCA A }\end{array}$ & 667 & 1 \\
\hline $\begin{array}{l}\text { sec forw. } \\
\text { sec rev. }\end{array}$ & $\begin{array}{l}\text { CTT GTA TGT ATG GAG } \\
\text { GAA TAA CAA } \\
\text { TGC AGG CAT CAT ATC } \\
\text { ATA CCA A }\end{array}$ & 284 & 1 \\
\hline $\begin{array}{l}\text { sed forw. } \\
\text { sed rev. }\end{array}$ & $\begin{array}{l}\text { GTG GTG AAA TAG ATA } \\
\text { GGA CTG C } \\
\text { ATA TGA AGG TGC TCT } \\
\text { GTG G }\end{array}$ & 385 & 2 \\
\hline $\begin{array}{l}\text { see forw. } \\
\text { see rev. }\end{array}$ & $\begin{array}{l}\text { TAC CAA TTA ACT TGT GGA } \\
\text { TAG AC } \\
\text { CTC TTT GCA CCT TAC CGC }\end{array}$ & 171 & 2 \\
\hline $\begin{array}{l}\text { seg forw. } \\
\text { seg rev. }\end{array}$ & $\begin{array}{l}\text { CGT CTC CAC CTG TTG } \\
\text { AAG G } \\
\text { CCA AGT GAT TGT CTA TTG } \\
\text { TCG }\end{array}$ & 328 & 2 \\
\hline $\begin{array}{l}\text { seh forw. } \\
\text { seh rev. }\end{array}$ & $\begin{array}{l}\text { CAA CTG CTG ATT TAG CTC } \\
\text { AG } \\
\text { GTC GAA TGA GTA ATC } \\
\text { TCT AGG }\end{array}$ & 359 & 1 \\
\hline $\begin{array}{l}\text { sei forw. } \\
\text { sei rev. }\end{array}$ & $\begin{array}{l}\text { CAA CTC GAA TTT TCA ACA } \\
\text { GGT ACC } \\
\text { CAG GCA GTC CAT CTC } \\
\text { CTG }\end{array}$ & 466 & 2 \\
\hline $\begin{array}{l}\text { sej forw. } \\
\text { sej rev. }\end{array}$ & $\begin{array}{l}\text { CAT CAG AAC TGT TGT TCC } \\
\text { GCT AG } \\
\text { CTG AAT TTT ACC ATC AAA } \\
\text { GGT AC }\end{array}$ & 142 & 1 \\
\hline $\begin{array}{l}16 S \text { rRNA } \\
\text { forw. } \\
16 S \text { rRNA } \\
\text { rev. }\end{array}$ & $\begin{array}{l}\text { GTA GGT GGC AAG CGT } \\
\text { TAT CC } \\
\text { CGC ACA TCA GCG TCA G }\end{array}$ & 228 & 1 and 2 \\
\hline
\end{tabular}

seh, sei genes; FRI913 for sea, sec, see genes; FRI445 for seg, sei genes; R4071/00 for seb gene; R4774/00 as a negative control. The mixes were submitted to a program performed on a thermocycler (Mycycler, BioRad) with an initial denaturation step at $94^{\circ} \mathrm{C}$ for $10 \mathrm{~min}, 31$ amplification cycles each with $1 \mathrm{~min}$ at $95^{\circ} \mathrm{C}, 45 \mathrm{~s}$ at $62{ }^{\circ} \mathrm{C}$ and $1 \mathrm{~min}$ at $72{ }^{\circ} \mathrm{C}$ followed by an additional extension step of $10 \mathrm{~min}$ at $72{ }^{\circ} \mathrm{C}$. PCR products supplemented with ethidium bromide were resolved by electrophoresis in $2 \% \mathrm{w} / \mathrm{v}$ agarose (0.04 M Tris-acetate, $0.001 \mathrm{M}$ EDTA, pH 8.0 ) at $50 \mathrm{~V}$, for $3 \mathrm{~h}$, using 100-1000 bp ladder molecular size markers (BioRad) as standards. DNA patterns were visualized on a UV transilluminator (Gel Documentation System 2000, BioRad).

\section{Antibiotic susceptibility test}

The minimal inhibitory concentrations (MICs $(\mu \mathrm{g} / \mathrm{mL})$ ) for $S$. aureus strains were determined by the agar dilution method described in the guidelines of the Clinical and Laboratory Standards Institute (CLSI, 2007). The inoculum was prepared from an overnight culture on TSA plates, by suspension in sterile Ringer's 
solution in order to obtain turbidity equivalent to 0.5 McFarland standard. The antibiotics investigated were penicillin G (Sigma, Spain), ampicillin (Fluka, Spain), vancomycin, nitrofurantoin, erythromycin, chloramphenicol (Sigma) and oxacillin (BioChemica, Spain); rifampicin, gentamicin, tetracycline and ciprofloxacin were kindly supplied by Labesfal, Portugal. The MIC was determined in Muller Hinton agar ( $\mathrm{MH}$, bioMérieux) plus $2 \% \mathrm{w} / \mathrm{v}$ of $\mathrm{NaCl}$ in the case of oxacillin, in cation-adjusted $\mathrm{MH}$ for penicillin $\mathrm{G}$ and ampicillin and in $\mathrm{MH}$ to test the other antibiotics investigated. S. aureus ATCC 29213 was plated as a control. For each antibiotic susceptibility determination, at least two independent experiments were performed.

\section{Other virulence factors}

Gelatinase activity was detected using a medium with $12 \% \mathrm{w} / \mathrm{v}$ of gelatine (10 g/L Yeast extract, $15 \mathrm{~g} / \mathrm{L}$ Tryptone, $120 \mathrm{~g} / \mathrm{L}$ gelatine from bovine skin; Sigma). After overnight growth on TSA, cultures were transferred to tubes containing $4 \mathrm{~mL}$ of medium containing gelatine. The tubes were incubated at $30^{\circ} \mathrm{C}$ for seven days. If the bacteria did not produce gelatinase the medium remained solid, while the presence of sufficient gelatinase turned the medium liquid even when placed in the refrigerator.

The hemolytic test was performed on blood agar plates (COS, Columbia agar plus $5 \% \mathrm{v} / \mathrm{v}$ sheep blood plates; bioMérieux). The strains were streaked onto the plates and incubated at $37^{\circ} \mathrm{C}$ for $1-2$ days. The presence or absence of zones of clearing around the colonies was interpreted as $\beta$-hemolysis (positive) or $\gamma$-hemolysis (negative) activity, respectively. Greenish zones around the colonies were interpreted as $\alpha$-hemolysis.

For each virulence factor tested, at least two independent experiments were performed.

\section{Results and discussion}

\section{Bacterial strains and media}

One hundred and forty seven strains were confirmed to be $S$. aureus when the gene nuc and the target $16 \mathrm{~S}$ rRNA were observed to be present simultaneously. The genotypic identification was totally in concordance with the results obtained for the phenotypic characterization namely, the Gram, Catalase and coagulase test and the presence of DNAse activity.

The gene mecA which has been reported to be responsible for methicillin resistance (Zhang et al., 2004; Bagcigil et al., 2007; Zaraket et al., 2007; Zhang et al., 2008) was determined during the genotypic identification step. According to our results, only $0.68 \%$ $(1 / 148)$ of the isolates showed the presence of the gene mecA (from bovine mastitis).

\section{Detection of enterotoxin production VIDAS test}

The VIDAS test for enterotoxin production was performed for all the strains; $40 \%$ of the tested strains were enterotoxigenic and were mainly isolated from fermented sausages (raw materials and fermented meat products; Table 2). Few of the strains originally isolated from cases of bovine mastitis and from raw milk were demonstrated to be enterotoxigenic by the VIDAS test ( 1 and 3 isolates, respectively). This methodology is known to be rapid and easy to perform but only detects the expression of staphylococcal enterotoxins SEA-SEE and cannot detect the SEs that have more recently been described by several authors (Kérouanton et al., 2007; Lawrynowicz-Paciorek et al., 2007; Chiang et al., 2008). In addition, this methodology only gives a positive or a negative result concerning the expression of the SE toxins A-E and does not differentiate between them.

\section{SE production and genes detection}

The results of the multiplex PCR analysis of all the 148 strains of S. aureus are shown in Table 2 . One or more se genes were carried by $69 \%$ of the isolates; $12 \%$ of these isolates possessed one kind of $s e$ gene, and the remaining $88 \%$ more than one se gene. Eleven se genotypes were observed, the most commonly detected were sea seg, sea seg sei and seg sei with 26, 23 and 25\% respectively. The isolates collected from cheeses, raw cow's milk and bovine mastitis, showed a lower incidence of se genes. On the other hand, the isolates obtained from fermented meat products showed higher incidence of types of enterotoxins.

The frequent detection of sea, seg and sei genes among S. aureus taken from a variety of sources, has already been demonstrated as having an association with food-poisoning outbreaks (Omoe et al.,

Table 2

Enterotoxin genes distribution among S. aureus isolates.

\begin{tabular}{|c|c|c|c|c|c|c|c|}
\hline & Fermented meat products & Raw meat & Cheeses & Bovine mastitis & Raw cow's milk & Other food products ${ }^{\mathrm{a}}$ & Total \\
\hline Total & $65(100 \%)$ & $15(100 \%)$ & $9(100 \%)$ & $18(100 \%)$ & $20(100 \%)$ & $20(100 \%)$ & $148(100 \%)$ \\
\hline \multicolumn{8}{|l|}{ VIDAS } \\
\hline se negative & $26(40 \%)$ & $6(40 \%)$ & $8(89 \%)$ & 17 (94\%) & $17(85 \%)$ & $14(70 \%)$ & $88(60 \%)$ \\
\hline se positive & $39(60 \%)$ & $9(60 \%)$ & $1(11 \%)$ & $1(6 \%)$ & $3(15 \%)$ & $6(30 \%)$ & $59(40 \%)$ \\
\hline \multicolumn{8}{|l|}{ Genotype } \\
\hline se negative & $16(25 \%)$ & $2(13 \%)$ & $1(11 \%)$ & $10(56 \%)$ & $13(65 \%)$ & $4(20 \%)$ & $46(31 \%)$ \\
\hline se positive & $49(75 \%)$ & $13(87 \%)$ & $8(89 \%)$ & $8(44 \%)$ & $7(35 \%)$ & $16(80 \%)$ & $101(69 \%)$ \\
\hline sea seg & $22(44 \%)$ & $1(7.7 \%)$ & - & - & - & $3(19 \%)$ & $26(26 \%)$ \\
\hline sea seg sei & $17(34 \%)$ & $4(30.8 \%)$ & - & - & - & $2(13 \%)$ & $23(23 \%)$ \\
\hline seg sei & $4(8 \%)$ & $4(30.8 \%)$ & $5(62.5 \%)$ & $5(63 \%)$ & $3(43 \%)$ & $4(25 \%)$ & $25(25 \%)$ \\
\hline sec-bovine & $1(2 \%)$ & - & - & - & $2(29 \%)$ & - & $3(3 \%)$ \\
\hline seg & - & $3(23 \%)$ & - & $2(25 \%)$ & - & $6(38 \%)$ & $11(11 \%)$ \\
\hline sea seg seh & $4(8 \%)$ & - & - & - & - & - & $4(4 \%)$ \\
\hline sec-bovine seg & $1(2 \%)$ & - & - & $1(12 \%)$ & $2(28 \%)$ & - & $2(2 \%)$ \\
\hline seg sei sed & - & - & $2(25 \%)$ & - & - & - & $2(2 \%)$ \\
\hline sec & - & - & $1(12.5 \%)$ & - & - & - & $1(1 \%)$ \\
\hline sea sec & - & - & - & - & - & $1(5 \%)$ & $1(1 \%)$ \\
\hline sed seg sei seh & $1(2 \%)$ & $1(7.7 \%)$ & - & - & - & - & $1(1 \%)$ \\
\hline
\end{tabular}

-; Not detected.

a Other food products (cheeses, bread, kitchen surfaces swab and pie). 
2002; Cha et al., 2006; Kérouanton et al., 2007). Our results are in agreement with the study performed by Lawrynowicz-Paciorek et al. (2007) which demonstrated that 74\% (39/53) of the isolates of S. aureus collected in Poland in the years 2004-2005, from various food products, were enterotoxigenic.

The results obtained for VIDAS SET methodology and for se genes detection were compared according to the presence of seasee genotypes determined by PCR. There was a correlation of $80 \%$ between the toxin types and the presence of respective genes. Concerning the other $20 \%$ of the isolates, one of these conditions was observed: the enterotoxin was expressed during growth but the gene was not detected (6\%); the gene was present and no expression was observed (4\%) and the VIDAS was positive for the expression of SEA-SEE but the gene detected by PCR was another one (10\%). Vernozy-Rozand et al. (2004) described differences in the specificity and in the sensitivity of the assays for the detection of staphylococcal enterotoxins from foods.

\section{Antibiotic susceptibility test}

Food is an important factor for the transfer of antibiotic resistances. Such transfer can occur by means of antibiotic residues in food, through the transfer of resistant food-borne pathogens or through the ingestion of resistant strains of the original food microflora and resistance transfer to pathogenic microorganisms (Khan et al., 2000; Pesavento et al., 2007). S. aureus strains are known to be frequently resistant to antibiotic therapy due to their capacity to produce an exopolysaccharide barrier and because of their location within microabscesses, which limit the action of drugs (Gündoğan et al., 2006).

The antimicrobial resistance profile of the tested $S$. aureus strains to different antibiotics was analysed; $15 \%$ of the isolates were sensitive to all the tested antibiotics and $51 \%$ of the strains were shown to be intermediate (according to CLSI, 2007) and/or resistant to at least 3 antibiotics (data not shown). The isolates collected from bovine mastitis and from raw cow's milk were demonstrated to be the most sensitive to the tested antibiotics (data not shown). No resistance to nitrofurantoin, vancomycin and ciprofloxacin was found. A small percentage of the isolates demonstrated resistance to rifampicin, gentamicin, erythromycin, chloramphenicol, and tetracycline (Table 3). Also resistance to $\beta$-lactams such as ampicillin, penicillin and oxacillin was evident 70,73 and $38 \%$ respectively. Previous studies have already discussed the resistance of $S$. aureus to $\beta$-lactams (Gündoğan et al., 2005; Kérouanton et al., 2007; Pesavento et al., 2007).

According to CLSI (2007) it was possible to conclude that $38 \%$ of the strains were potentially MRSA (MIC $\geq 6 \mu \mathrm{g} / \mathrm{mL}$ for oxacillin). However, these results were significantly different from those

Table 3

Antimicrobial susceptibility of $S$. aureus isolates.

\begin{tabular}{llll}
\hline & \multicolumn{2}{l}{ No (\%) of S. aureus isolates $(n=148)$} \\
\cline { 2 - 4 } & $\%$ S & \% I & \% R \\
\hline Erythromycin & $52(35 \%)$ & $89(60 \%)$ & $7(5 \%)$ \\
Gentamicin & $136(92 \%)$ & $9(6 \%)$ & $3(2 \%)$ \\
Tetracycline & $147(99.3 \%)$ & - & $1(0.7 \%)$ \\
Chloramphenicol & $(127) 85.8 \%$ & $19(12.8 \%)$ & $2(1.4 \%)$ \\
Ciprofloxacin & $(145) 98 \%$ & $3(2 \%)$ & - \\
Rifampicin & $(147) 99.3 \%$ & - & $1(0.7 \%)$ \\
Ampicillin & $44(30 \%)$ & NA & $104(70 \%)$ \\
Penicillin & $40(27 \%)$ & NA & $108(73 \%)$ \\
Oxacillin & $92(62 \%)$ & NA & $56(38 \%)$ \\
Vancomycin & $133(90 \%)$ & $15(10 \%)$ & - \\
Nitrofurantoin & $141(95 \%)$ & $7(5 \%)$ & - \\
\hline
\end{tabular}

-, Not detected; S, Sensitive; I, Intermediate; R, Resistant; NA, Not applied. obtained by PCR, in which the gene mecA was detected in only $0.68 \%$ of the isolates. According to the CFSPH (2006) report, the definition of MRSA when using antibiotic can overestimate methicillin resistance. Despite the standardized recommendations for the susceptibility testing of MRSA, Lee et al. (2004) demonstrated that some of the isolates that did not carry mecA gene were considered phenotypically resistant to oxacillin (MRSA) and that the phenotypic expression of resistance can vary depending on the cellular growth conditions.

In the present work, $19 \%(28 / 148)$ of the tested isolates were both enterotoxigenic and oxacillin positives.

A correlation was observed between the antibiotic resistance profile of the strains isolated from cases of bovine mastitis and from the raw cow's milk; in general, these specific isolates were demonstrated to be resistant to penicillin and ampicillin and more sensitive to the other antibiotics (data not shown) possibly as a result of treating mastitis cases with $\beta$-lactams. In the case of isolates from fermented sausages, a higher overall resistance to antibiotics was observed (again possibly from using antibiotics as growth promoters in animal feed).

\section{Virulence factors}

Except for 4 isolates (3\%), all were gelatinase positive; $81 \%$ were demonstrated to be $\beta$-hemolytic, $8 \%$ were $\alpha$-hemolytic, $11 \%$ were $\gamma$ hemolytic. Recently, El-Jakee et al. (2008) reported that $92.3 \%$ of the $S$. aureus isolates (from different sources) were positive for the gelatinase test; $89.7 \%$ were hemolytic in sheep blood agar and that $10.3 \%$ were non-hemolytic. These results are in agreement with the present study.

\section{Conclusion}

S. aureus is well established as a clinical and epidemiological pathogen; in this study it was demonstrated that the potentially pathogenic role of $S$. aureus as a food-borne pathogen should not be neglected. Antibiotic-resistant isolates might be transmitted to humans by the consumption of food products containing such resistant and multiresistant bacteria and that the use of antibiotics as growth promoters in animal husbandry, especially of those commonly used for both human and animal care, should be avoided (Swann, 1969; Wise, 2007).

In conclusion, these findings highlight the high potential risk for consumers in the absence of strict hygienic and preventative measures to avoid the presence of $S$. aureus isolates and SEs production in foods, emphasising the need for improved hygiene practices during food processing and also during the distribution and consumption of the final food products.

\section{Acknowledgements}

This work was supported by the European Economic Community IP016264-2 project "TRUE FOOD, Traditional United Europe Food".

\section{References}

Aires de Sousa, M., Van Leeuwen, W., Verbrugh, H., Sanches, I.S., Van Belkum, A., Lencastre, H., 1996. Characterization of methicillin-resistant Staphylococcus aureus isolates from Portuguese hospitals by multiple genotyping methods. Microb. Drug Resist. 2, 331-341.

Ardic, N., Sareyyupoglu, B., Ozyurt, M., Haznedaroglu, T., Ilga, U., 2006. Investigation of aminoglycoside modifying enzyme genes in methicillin-resistant staphylococci. Microbiol. Res. 161, 49-54.

Bagcigil, F.A., Moodley, A., Baptiste, K.E., Jensen, V.F., Guardabassi, L., 2007. Occurrence, species distribution, antimicrobial resistance and clonality of methicillin- 
and erythromycin-resistant staphylococci in the nasal cavity of domestic animals. Vet. Microbiol. 121, 307-315.

Cha, J.O., Lee, J.K., Jung, Y.H., Yoo, J.I., Park, Y.K., Kim, B.S., Lee, Y.S., 2006 Molecular analysis of Staphylococcus aureus isolates associated with staphylococcal food poisoning in South Korea. J. Appl. Microbiol. 101, 864871.

Chiang, Y., Chang, L.T., Lin, C.W., Yang, C.Y., Tsen, H.Y., 2006. PCR primers for the detection of Staphylococcal enterotoxins (SEs) K, L, M and survey of SEs types in Staphylococcus aureus isolates from food-poisoning cases in Taiwan. J. Food Protect. 69, 1072-1079.

Chiang, Y., Liao, W., Fan, C., Pai, W., Chiou, C., Tsen, H., 2008. PCR detection of Staphylococcal enterotoxins (SEs) N, O, P, Q, R, U, and survey of SE types in Staphylococcus aureus isolates from food-poisoning cases in Taiwan. Int. J. Food Microbiol. 121, 66-73.

CLSI, Clinical and Laboratory Standards Institute, 2007. Performance Standards for Antimicrobial Susceptibility Testing; Fifteenth Informational Supplement. CLSI document M100-S15. Clinical and Laboratory Standards Institute, Wayne, PA

CFSPH, Center of Food Security \& Public Health, 2006. Methicillin Resistant Staphylococcus aureus. Institute for International Cooperation in Animal Biologics. www.cfsph.iastate.edu.

El-Jakee, J., Nagwa, A.S., Bakry, M., Zouelfakar, S.A., Elgabry, E., El-Said, W.A.G., 2008. Characteristics of Staphylococcus aureus strains isolated from human and animal sources. American-Eurasian J. Agric. Environ. Sci. 4, 221-229.

Gündoğan, N., Citak, S., Yucel, N., Devren, A., 2005. A note on the incidence and the antibiotic resistance of Staphylococcus aureus isolated from meat and chicken samples. Meat Sci. 69, 807-810.

Gündoğan, N., Citak, S., Turan, E., 2006. Slime production, DNAse activity and antibiotic resistance of Staphylococcus aureus isolated from raw milk, pasteurised milk and ice cream samples. Food Control 17, 389-392.

Ho, P., Chuang, S., Choi, Y., Lee, R.A., Lit, A.C.H., Ng, T., Que, T., Shek, K., Tong, H., Tse, C.W.S., Tung, W., Yung, R.W.H., 2008. Community-associated methicillinresistant and methicillin-sensitive Staphylococcus aureus: skin and soft tissue infections in Hong Kong. Diagn. Microbiol. Infect. Dis. 61, 245-250.

Khan, S.A., Nawaz, M.S., Khan, A.A., Cerniglia, C.E., 2000. Transfer of erythromycin resistance from poultry to human clinical strains of Staphylococcus aureus. J. Clin. Microbiol. 38, 1832-1838.

Kérouanton, A., Hennekinne, J.A., Letertre, C., Petit, L., Chesneau, O., Brisabois, A. Buyser, M.L.D., 2007. Characterization of Staphylococcus aureus strains associated with food poisoning outbreaks in France. Int. J. Food Microbiol. 115, 369375.

Kuroda, M., Nagasaki, S., Ito, R., Ohta, T., 2007. Sesquiterpene farnesol as a competitive inhibitor of lipase activity of Staphylococcus aureus. FEMS Microbiol. Lett. 273, 28-34.

Lawrynowicz-Paciorek, M., Kochman, M., Grochowska, A., Windyga, B., 2007. The distribution of enterotoxin and enterotoxin-like genes in Staphylococcus aureus strains isolated from nasal carriers and food samples. Int. J. Food Microbiol. 117, 319-323.

Lee, J.H., Jeong, J., Park, Y., Choi, S., Kim, Y., Chae, J., Moon, J., Park, H., Kim, S., Eo, S., 2004. Evaluation of the methicillin-resistant Staphylococcus aureus (MRSA)screen latex agglutination test for detection of MRSA of animal origin. J. Clin. Microbiol. 42, 2780-2782.

Løvseth, A., Loncarevic, S., Berdal, K., 2004. Modified multiplex PCR method for detection of pyrogenic exotoxin genes in staphylococcal isolates. J. Clin. Microbiol. 42, 3869-3872.

Martin, M.C., González-Hevia, M.A., Mendoza, M.C., 2003. Usefulness of a two-step PCR procedure for detection and identification of enterotoxigenic staphylococci of bacterial isolates and food samples. Food Microbiol. 20, 605-610.
Mee-Marquet, N.V., Blanchard, M., Domelier, A.S., Quentin, R., Survey Study Group of the Relais dHygiène du Centre, 2004. Virulence and antibiotic susceptibility of Staphylococcus aureus strains isolated from various origins. Pathol. Biol. 52, 579-583.

Monday, S.R., Bohach, G.A., 1999. Use of multiplex PCR to detect classical and newly described pyrogenic toxin genes in staphylococcal isolates. J. Clin. Microbiol. 37, 3411-3414.

Nejma, M.B., Mastouri, M., Frih, S., Sakly, N., Salem, Y.B., Nour, M., 2006. Molecular characterization of methicillin-resistant Staphylococcus aureus isolated in Tunisia. Diagn. Microbiol. Infect. Dis. 55, 21-26.

Normanno, G., Salandra, G.L., Dambrosio, A., Quaglia, N.C., Corrente, M., Parisi, A., Santagada, G., Firinu, A., Crisetti, E., Celano, G.V., 2007. Occurrence, characterization and antimicrobial resistance of enterotoxigenic Staphylococcus aureus isolated from meat and dairy products. Int. J. Food Microbiol. 115, 290-296.

Omoe, K., Ishikawa, M., Shimoda, Y., Hu, D., Ueda, S., Shinagawa, K., 2002. Detection of seg, seh and sei genes in Staphylococcus aureus isolates and determination of the enterotoxin productivities of $S$. aureus isolates harbouring seg, seh or sei genes. J. Clin. Microbiol. 40, 857-862.

Omoe, K., Imanishi, K., Hu, D., Kato, H., Fugane, Y., Abe, Y., Hamaoka, S., Watanabe, Y., Nakane, A. Uchiyama, T., Shinagawa, K., 2005. Characterization of novel staphylococcal enterotoxin-like toxin type P. Infect. Immun. 73, 5540-5546.

Pesavento, G., Ducci, B., Comodo, N., Nostro, A.L., 2007. Antimicrobial resistance profile of Staphylococcus aureus isolated from raw meat: a research for methicillin resistant Staphylococcus aureus (MRSA). Food Control 18, 196-200.

Sandel, M.K., McKillip, J.L., 2004. Virulence and recovery of Staphylococcus aureus relevant to the food industry using improvements on traditional approaches. Food Control 15, 5-10.

Swann, M., 1969. Report of the Joint Committee on the Use of Antibiotics in Anima Husbandry and Veterinary Medicine. Cmnd 4190. H.M.S.O., London.

Tsen, H.Y., Yu, G.K., Wang, K.C., Wang, S.J., Chang, M.Y., Lin, L.Y., 1998. Comparison of the enterotoxigenic types, toxic shock syndrome toxin I (TSST-1) strains and antibiotic susceptibilities for enterotoxigenic Staphylococcus aureus strains isolated from food and clinical samples. Food Microbiol. 15, 33-41.

Vancraeynest, D., Hermans, K., Haesebrouck, F., 2007. Prevalence of genes encoding exfoliative toxins, leucotoxins and superantigens among high and low virulence rabbit Staphylococcus aureus strains. Vet. Microbiol. 121, 368-372.

Vernozy-Rozand, C., Mazuy-Cruchaudet, C., Bavai, C., Richard, Y, 2004 Comparison of three immunological methods for detecting staphylococcal enterotoxins from food. Lett. Appl. Microbiol. 39, 490-494.

Wise, R.E., 2007. Combating antimicrobial resistance: the role of the Specialist Advisory Committee on Antimicrobial Resistance. J. Antimicrob. Chemother. 60 (Suppl. 1), i5-i7.

Zaraket, H., Otsuka, T., Saito, K., Dohmae, S., Takano, T., Higuchi, W., Ohkubo, T. Ozaki, K., Takano, M., Reva, I., Baranovich, T., Yamamoto, T., 2007. Molecular characterization of methicillin-resistant Staphylococcus aureus in hospitals in Niigata, Japan: divergence and transmission. Microbiol. Immunol. 51, 171-176.

Zhang, K., Sparling, J., Chow, B.L., Elsayed, S., Hussain, Z., Church, D.L., Gregson, D.B. Louie, T. Conly, J.M. 2004. New quadriplex PCR assay for detection of methicillin and mupirocin resistance and simultaneous discrimination of Staphylococcus aureus from coagulase-negative staphylococci. J. Clin. Microbiol. 42, 4947-4955.

Zhang, K., McClure, J., Elsayed, S., Louie, T., Conly, J.M., 2008. Novel multiplex PCR assay for simultaneous identification of community-associated methicillinresistant Staphylococcus aureus strains USA300 and USA400 and detection of mecA and Panton-Valentine leukocidin genes, with discrimination of Staphylococcus aureus from coagulase-negative staphylococci. J. Clin. Microbiol. 46 1118-1122. 